\title{
Rasmussen Subacute Encephalitis
}

National Cancer Institute

\section{Source}

National Cancer Institute. Rasmussen Subacute Encephalitis. NCI Thesaurus. Code C125384.

A rare, progressive chronic inflammation of a single cerebral hemisphere that usually affects children. It is characterized by severe seizures, loss of motor skills and speech, hemiparesis, and dementia. 